\title{
Coordinated Planning and Energy Conservation for Distribution Network with Renewable Energy: Standardized Information Model and Software
}

\author{
Tianlin Wang, ${ }^{1}$ Huazhen Cao, ${ }^{1}$ Chong Gao, ${ }^{1}$ Zhuohuan Li, ${ }^{2}$ Tao Yu $\left(\mathbb{D},{ }^{2}\right.$ and Ran Cheng \\ ${ }^{1}$ Grid Planning \& Research Center, Guangdong Power Grid Co., Ltd., CSG, Guangzhou 510030, China \\ ${ }^{2}$ Electric Power College of South China University of Technology, Guangzhou 510640, China \\ Correspondence should be addressed to Tao Yu; taoyu1@scut.edu.cn
}

Received 30 April 2021; Accepted 28 May 2021; Published 12 June 2021

Academic Editor: Bo Yang

Copyright (C) 2021 Tianlin Wang et al. This is an open access article distributed under the Creative Commons Attribution License, which permits unrestricted use, distribution, and reproduction in any medium, provided the original work is properly cited.

In recent years, energy conservation and environmental protection have attracted great attention by the state, and many efforts have been made from the policy and planning level. In view of the current distribution network planning requirements about energy-saving and environmental protection attributes such as loss reduction, carbon reduction, and environmental friendliness, this study proposes a set of energy-saving and environmental protection evaluation indicators for distribution network. Then, the CIM file library is constructed for typical equipment. Based on the CIM file, the digital planning technology for distribution network is designed. Besides, the feature library of energy conservation and environmental protection indicators, power flow calculation module, carbon flow calculation module, and renewable energy integration planning module are described.

\section{Introduction}

In December 2016, China issues the development plan for energy conservation and environmental protection industries during the 13th five-year plan period, which points out that environmentally friendly industries are the key to promote economic growth and enhance green competitiveness, as well as support ecological conservation. And, the development and reform commission of Guangdong province proposes the 13th five-year plan for energy development of Guangdong province (2016-2020) in January 2017, which puts forward the development goals of improving the green and low-carbon energy system, promoting energy conservation, and reducing carbon emission. Meanwhile, Guangdong province government presents that it is vital to implement energy-saving and low-carbon power dispatching considering economic, energy-saving, and environmental protection factors and then make the reasonable competition rules of power market. Besides, China Southern Power Grid Corporation has established a complete index evaluation system about energy conservation and environmental protection, which helps to combine market transaction with energy-saving and low-carbon power dispatching. Hence, it can be predicted that improving renewable energy penetration rate, developing low-carbon planning technology, and promoting distributed energy (such as solar, wind, and geotherm) are the development trends of the power system in the future [1-3].

Distribution network is the link between the power plant and end users. The scientific planning of distribution network can ensure the reasonable structure and economical operation of the power grid. Moreover, it is important to realize dual carbon control (carbon peaking and carbon neutralization) of the power system by improving the power supply quality, improving environment, and optimizing energy consumption structure. From the perspective of planning, electric energy should be delivered to the user terminal with high quality. And, the reliable supply of electric energy is supported by large-scale distribution equipment. Therefore, the economic and technical costbenefit analysis of distribution network investment is essential for the efficient and economic operation of the power 
system [4]. From the perspective of operation, the voltage at the load side of distribution network is low with large load current, which makes the loss of transformers and lines. These power losses even can reach about $10 \%$ or even higher of the transmission power. Hence, the energy-saving and loss reduction measures should be carried out to improve the economic operation level and equipment utilization rate of distribution network [5].

Recently, higher requirements have been raised for distribution network planning with the economy development, power system reformation, and energy conservation and environmental protection initiative. Distribution network planning not only requires the minimize the construction and operation costs with the safe and reliable power supply but also concentrates on the coordination between distribution network and environment to reduce carbon emission and protect environment [6]. At present, lots of works on energy saving and loss reduction of distribution network [7-9] have been studied, which design a series of new technologies and equipment and establish the relevant evaluation index. However, these research studies ignore the environmental problems in the construction and operation of distribution network equipment, such as the greenhouse effect caused by sulfur dioxide, nitrogen oxide, and carbon dioxide emission. On the contrary, the electromagnetic radiation from distribution transformer, overhead lines, and cable lines may affect nearby residents which leads to a great deal of criticism. Furthermore, the research on renewable energy access planning of distribution network mainly includes planning algorithm [10-12], planning model [13-15], renewable energy siting and sizing [16-20], and collaborated planning between renewable energy and power system [21, 22]. And, the evaluation indexes and intelligent planning software of distribution network environmental protection planning need to be further studied.

To make up for the above deficiencies, this paper establishes an index system that can guide the distribution network planning and evaluate the energy conservation and environmental protection attributes. Then, a typical equipment library is established to systematically model the distribution network equipment based on the CIM file. Finally, the function modules of energy-saving and environmental protection software are designed which lays the foundation for the digital distribution network planning.

\section{Energy Conservation and Environmental Protection Indexes}

The purpose of establishing the index system is to better evaluate the energy conservation and environmental protection characteristics of the distribution network, and the following content will analyse and elaborate on these two aspects.

2.1. Energy Conservation Indexes. Energy conservation indexes mainly include equipment life cycle, line loss, equipment loss, and operation loss; the structure of them is shown in Figure 1. In particular, the whole life cycle denotes the overall costs of equipment (such as transformer, overhead line, cable line, circuit breaker, load switch, switch cabinet, outdoor switch box, cable distribution box, ring network cabinet, reactive power compensation device, and lightning rod) from production to recycle. Line loss and equipment loss fully describe the actual operation loss caused by line heating and equipment heating in the actual operation of distribution network. Moreover, the threephase unbalanced additional loss, unreasonable operating voltage additional loss, high-order harmonic additional loss, and equipment aging additional loss should be further considered in the operational additional level.

\subsection{Environmental Protection Indexes. Environmental} protection indexes mostly compose of equipment environmental protection index, high harmonic content, green distribution network index, carbon emission flow, and electric energy substitution index; the sketch map of them is given in Figure 2. Specially, equipment environmental protection index focuses on the radiation intensity and noise intensity. And, the distributed power penetration rate, electric vehicle charging (replacement) power station area density, capacity proportion of public electric vehicle charging and swapping facilities, annual consumption rate of distributed power generation, and cost of waste gas treatment in distribution network, as well as green equipment proportion, are the subindexes of the green distribution network indicator. In addition, the carbon emission stream regards the carbon emission flow rate and node carbon potential as the evaluation criterion. And, the electricity substitution index denotes the potential of "replace oil, gas, and coal with electricity."

\section{CIM File and Its Analytical Process}

The CIM model is a collection of various subsystems, and the main purpose of using CIM file is to establish a unified and standard information model to provide effective model support for distribution network research and planning. It is necessary to determine the relationship between each subsystem and then build an integrated framework that is easy to understand for users. There are three kinds of CIM models:

(1) Core model: this model is the basic to describe and analyse management system. It defines the control range of each subsystem, which also is the starting point of all the public models.

(2) General model: this model is independent of the system, which helps to develop management applications such as setting program and Internet program.

(3) Extended model: this model is a technical extension of the general model, which is mostly used in the specific environment.

As an information-based model, designers can realize visual CMI modelling through unified modelling language 


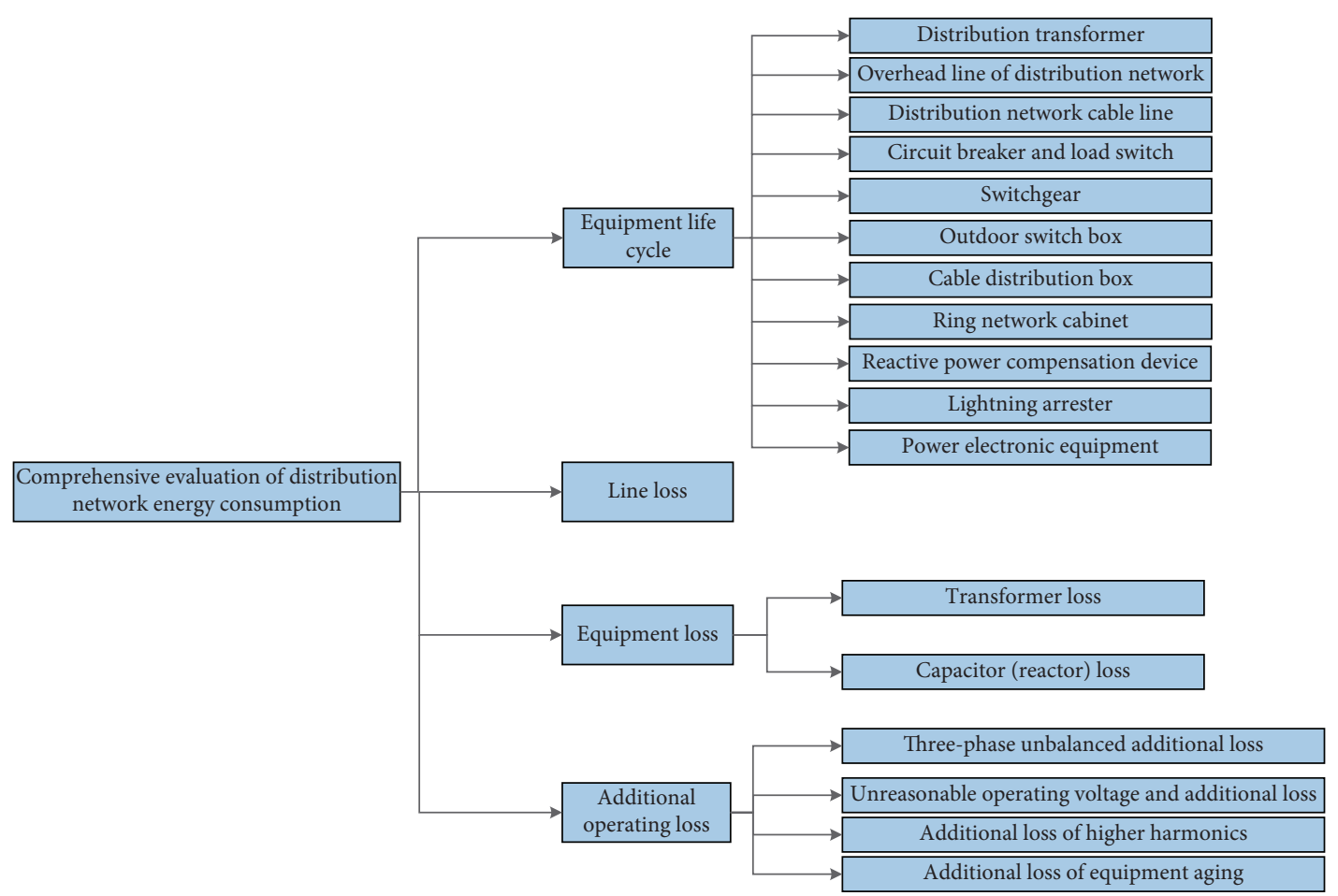

FIgURE 1: The diagram of the energy conservation index system.

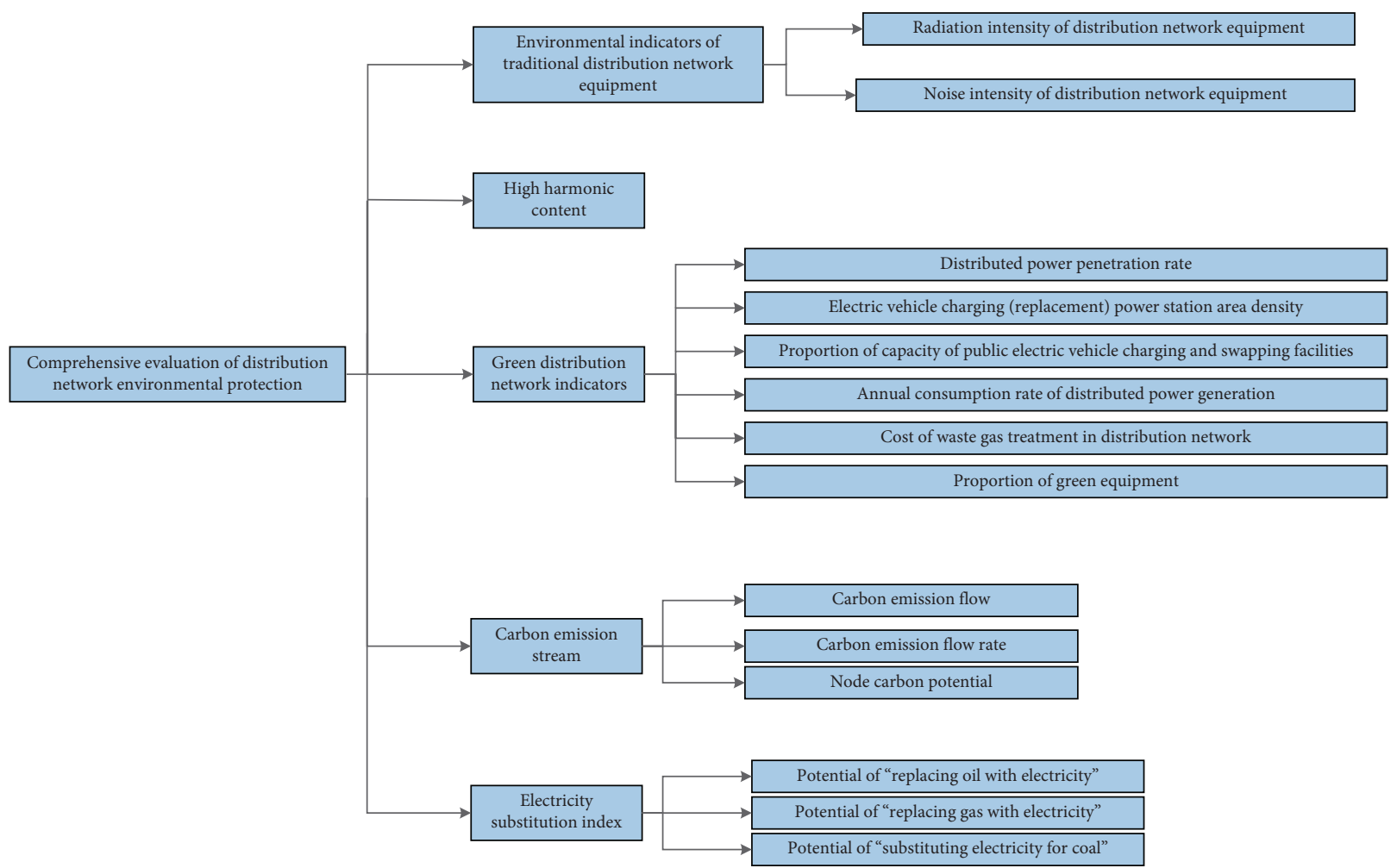

Figure 2: The diagram of the environmental protection index system.

(UML). The autoinformation exchange of the CIM model is achieved by Internet; then, an intelligent distribution network planning technology can be established. Besides, the CIM model avoids the problem of large subclasses caused by various definitions. The generic class is used to identify the attribute of each subclass and their name. Hence, this model can describe the specific attribute of monitoring content via integer, Boolean variable, floating-point number, string, etc. 
This paper analyses the CIM file and investigates the main objects involved in the distribution network planning. Then, the following analytical process of the CIM file can be given:

(1) Read CIM file and extract CIM component object, including station, wire, bus, switch, transformer, and terminal

(2) Find the connected component according to the terminal head of circuit breaker

(3) Determine the terminal head according to the component and read the component set

(4) Traverse component set and identify bus node, distribution node, and contact switch

(5) Repeat step (4) until the recursive traversal is completed

(6) Implement skeleton analysis including the main line marking and the insufficient assessment of main cross section and branch line; then, the problem library can be generated

(7) SVG element node mapping

(8) Save CIM data in library

\section{CIM File Library of Typical Distribution Network Equipment}

The distribution network model usually has large data and complex structure. And, the theory and practice of this paper are based on the modelling of power grid equipment (e.g., topology, line, load, equipment, and feeder), which can be described as follows:

(1) Line model: the line model can be classified according to the conductor type, wiring method, conductor kind, and wire style. However, the definition of the conductor type shows that this model is only suitable for the three-phase symmetric system which employs positive sequence and zero sequence components to describe line impedance. And, the distribution system is three-phase asymmetric system, which needs to consider more geometric attributes, electrical attributes, and electrical information to establish the integrated line model.

(2) Transformer model: the transformer model is composed of equipment container, transformer winding, and so on. In the CIM model, the winding type of the transformer is replaced by the end type which is associated with star impedance type and admittance type to represent the parameter matrix of the transformer.

(3) Load model: this model depicts the load of the power grid, which is able to (a) show the characteristics of load access point, (b) express multiphase connection and its connection type, (c) reflect constant impedance, constant power, and constant current load, and (d) represent three-phase balance and threephase imbalance in distribution network.
(4) Feeder model: The feeder model is extended by the CIM model. Feeder is a combination of power lines with the same voltage level in the distribution network which contains lots of power equipment. And, feeder modelling can build the overall or partial relationship between composite equipment and single equipment in distribution network.

\section{The Design of Coordinated Planning and Energy Conservation Software}

This proposed software is a novel distribution network planning technology, which can realize the digital and intelligent planning and decision-making with renewable energy connected. And, the energy conservation and environment protection factors are fully considered to satisfy the requirement of green distribution network construction. The algorithms and functions of the platform are compiled from the bottom layer, packaged, and encapsulated so that the platform interface can call these function packages. The system login page and technical framework are shown in Figures 3 and 4, respectively.

Moreover, the design of this software mainly includes four modules: energy-saving and environmental protection indexes feature library, power flow calculation, carbon flow calculation, and renewable energy connected planning.

\subsection{Energy-saving and Environmental Protection Indexes'} Feature Library. This library is dynamic which stores the typical energy-saving and environmental protection indexes from the engineering cases. The prominent advantage of this library is that the computation efficiency of software and the data capacity of library are improved simultaneously. Specially, the scale of database is increased based on the outcomes of engineering cases' analysing. Then, the engineering cases can extract characteristic data from the library to estimate the relevant indexes of equipment which saves computation time in large.

And, the visual interface of the indictor feature library is given in Figure 5. It is observed that the energy-saving and environmental protection indexes are exhibited via analysing engineering cases. And, the database can be continuously enriched by the increasing engineering cases to establish indictor feature library of equipment.

5.2. Power Flow Calculation. CIM expand package defines the connection mode of each equipment in distribution network, which can be described by "equipment-terminal-connection point." The terminal is the end of the device. A device has multiple terminals, and the connection point aggregates the related terminals without impedance according to network operation status. Taking the model library of the network layer as the middle layer, the CIM model is analysed to the middle layer database and a real-time synchronous computing database can be generated to achieve the automatic modelling of the whole physical model. Besides, the interface layer is established based on the secondary development and encapsulation of API 


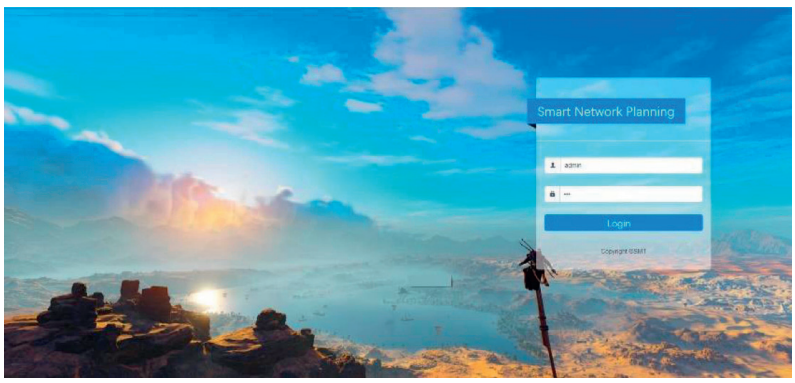

FIgURE 3: The system login page.

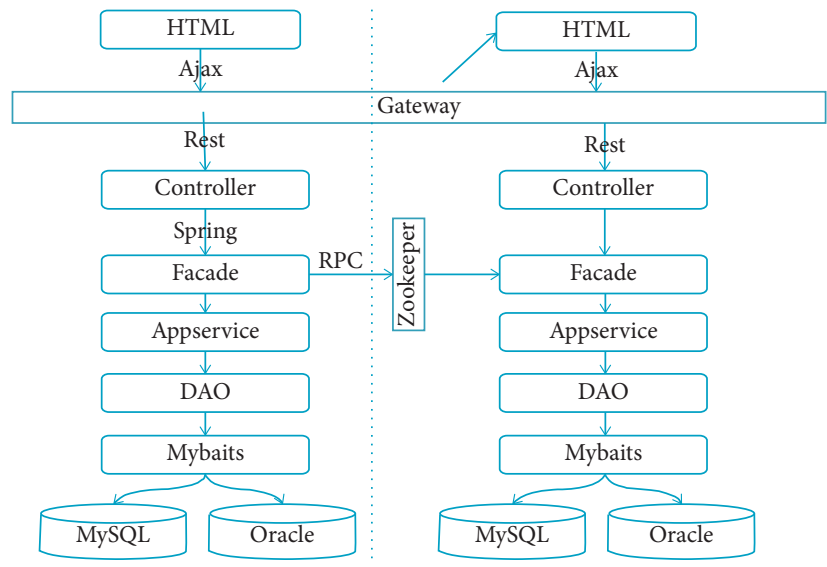

FIgURE 4: The overall technical framework.

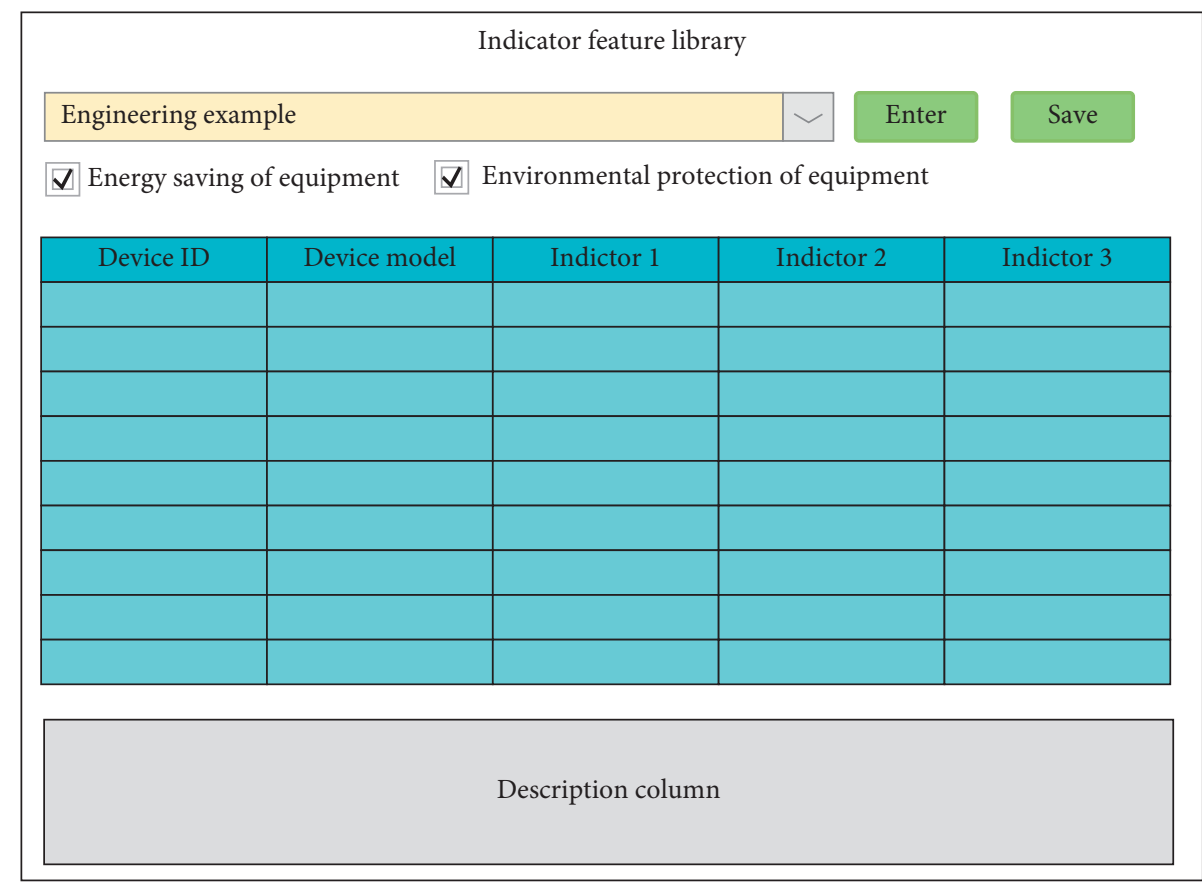

FIgURE 5: The visual interface of indictor feature library.

interface, which can realize the auto-periodic operation of power flow calculation.

The graph-based network topology subsystem can identify electrical equipment, which also supports the automatic topology program calling, network topology analysing, node numbering, and topology results updating. And, this system has the function of automatic network tracking, state network analysing, dynamic network diving, and region segmenting. 
The power flow calculation module is a built-in calculation module. Its calculation parameters are obtained by parse CIM file with distribution network information. Then, the relevant calculation parameters are input to the power flow calculation interface. And, the final calculation results are output and displayed on the front-end topology interface via the built-in calculation module developed by Python language. The power flow calculation module is compiled from the bottom of the code by us, without the use of software packages from other institutions or companies.

5.3. Carbon Flow Calculation. The carbon flow calculation module mainly involves the following indicators.

5.3.1. Branch Carbon Flow. The branch carbon flow is the most basic physical quantity of carbon flow, which is represented by $F$. It is defined as the cumulative amount of carbon emission corresponding to the carbon flow that passes through a branch along with the load flow in the given time. And, the unit of carbon flow is the same as carbon emission.

5.3.2. Branch Carbon Flow Rate. The carbon flow rate of a branch in unit time is called the branch carbon flow rate, which is represented by $R$. Its value is equal to the derivative of the branch carbon flow, and the unit is $\mathrm{t} \cdot \mathrm{CO}_{2} / \mathrm{h}$ or $\mathrm{kg} \cdot \mathrm{CO}_{2} / \mathrm{s}$ :

$$
R=\frac{\mathrm{d} F}{\mathrm{~d} t} .
$$

5.3.3. Branch Carbon Flux Density. The carbon emission flow of the power system is related to active power flow, so it is necessary to combine the above concepts to implement research. The branch carbon flux density is defined as the ratio of the carbon flow rate to the active power flow in a branch, which can be denoted by $\rho$. It is easy to find that the unit of branch carbon flow density is the same as the carbon emission intensity on the power generation side, i.e., $\mathrm{kg} \cdot \mathrm{CO}_{2} / \mathrm{kWh}$.

5.3.4. Node Carbon Potential. The node carbon potential of the power system describes the linear relationship between the carbon flow and the active power flow through a node, which is written as $e$. And, the expression is given by

$$
e_{n}=\frac{\sum_{i \in N^{+}} P_{i} \rho_{i}}{\sum_{i \in N^{+}} P_{i}}=\frac{\sum_{i \in N^{+}} R_{i}}{\sum_{i \in N^{+}} P_{i}}
$$

where $N^{+}$is the set of all branches whose flow flows into node $n$ and $i$ is the branch number. It can be observed that the unit of node carbon potential is the same as branch carbon flux density, and its value is equal to the weighted average of carbon flow density $\rho_{i}$ of the branches flowing into node $n$ for the active power flow $P_{i}$.

The essence of the power system carbon emission flow calculation is to quantitatively determine the flow state of carbon emission flow based on load flow distribution. The differences and relation between load flow analysing and carbon emission flow analysing can be summarized as follows: (a) the carbon emission flow depends on the existence of load flow, and the factors affecting load flow distribution also will have an impact on carbon emission flow; (b) the carbon emission flow is related to the carbon emission characteristics of the generator unit. Therefore, the carbon emission flow is not only restricted by load flow distribution but also affected by some parameters and boundary conditions about the generator unit.

The active power, reactive power, voltage, and phase angle of all nodes, as well as the load flow of all branches, can be obtained via the load flow calculation based on the CIM file. According to the nature of carbon emission flow, the carbon flow density on the all branches is equal to the carbon potential of the node connected to the branches. When the carbon potential of all nodes is obtained, the carbon flow rate of all branches can be calculated from the carbon potential of the starting node and branch load flow. Then, the carbon flow rate of each branch and key section can be acquired based on the carbon potential of each node.

Similar to the load flow calculation module, carbon flow calculation is carried out by the built-in calculation module using Python language, and the calculation outcomes are shown in the front-end topology interface (see Figure 6). Moreover, two practical engineering cases are introduced to assess the performance of designed load flow and carbon flow calculation platform. And, the sketch maps of these engineering cases are shown in Figure 7. Note that the detailed information is hidden in the maps due to confidentiality needs. Besides, the display interface of calculated feeders is denoted in Figure 8.

5.4. Renewable Energy Connected Planning. With the advancement and popularization of power electronics technology and the continuous advancement of China's energy conservation and emission reduction strategy, the scale and proportion of new energy access to the distribution network is increasing. In order to cope with the situation that the proportion of new energy access in the distribution network has increased year by year in recent years, the new energy access module is designed here.

The photovoltaic system has an important role and large market in distribution network with renewable energy connected. Hence, this proposed module is developed considering solar power.

Photovoltaic cell is the basic component of photovoltaic system, and its output power value is related to energy conversion efficiency, solar irradiation, panel area, and so on. The active power of the photovoltaic system can be approximately expressed as follows:

$$
P_{\mathrm{PV}}=r A \eta,
$$

where $A$ is panel area, $r$ is solar irradiation, and $\eta$ is energy conversion efficiency. 


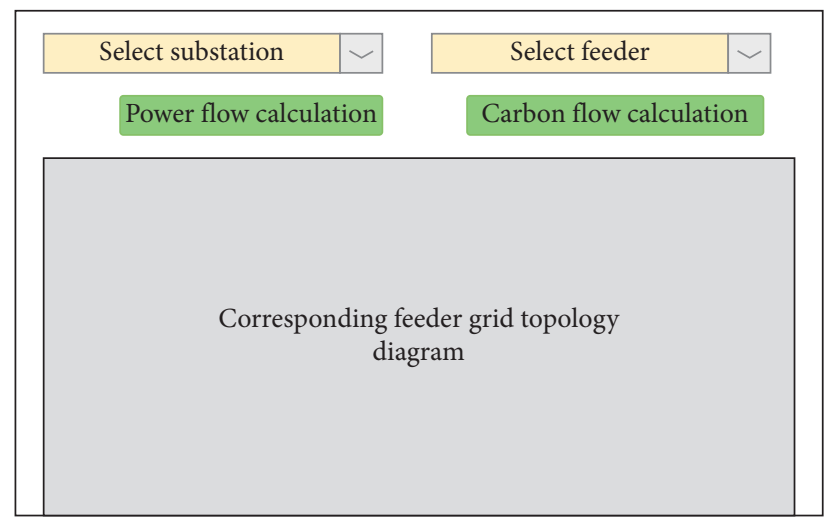

FIgURE 6: The visual interface of the carbon flow calculation module.

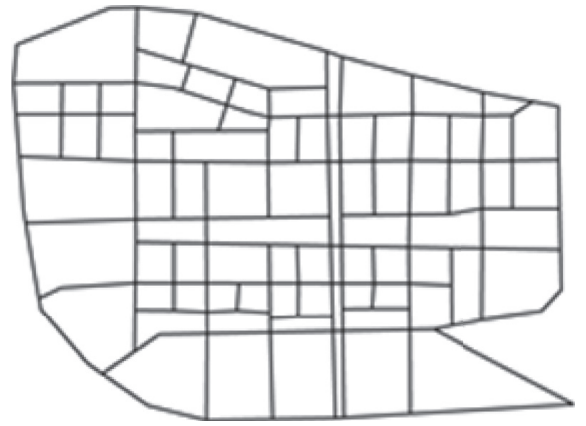

(a)



(b)

Figure 7: The sketch maps of two engineering cases. (a) Case one. (b) Case two.

The photovoltaic system usually works in the daytime. And, the solar irradiation meets beta distribution, and probability density it is

$$
f(r)=\frac{\Gamma(\alpha+\beta)}{\Gamma(\alpha) \Gamma(\beta)}\left(\frac{r}{r_{\max }}\right)^{\alpha-1}\left(1-\frac{r}{r_{\max }}\right)^{\beta-1},
$$

where $r_{\max }$ is the maximum solar irradiation and $\alpha$ and $\beta$ both are the shape parameters of beta distribution.

Therefore, the probability density of output power is given by

$$
f\left(P_{\mathrm{PV}}\right)=\frac{\Gamma(\alpha+\beta)}{\Gamma(\alpha) \Gamma(\beta)}\left(\frac{P_{\mathrm{PV}}}{P_{\max }}\right)^{\alpha-1}\left(1-\frac{P_{\mathrm{PV}}}{P_{\max }}\right)^{\beta-1} .
$$

The idea of the photovoltaic module based on the CIM file is to establish a front-end input interface. Then, the model and parameters of photovoltaic equipment can be input manually or read in the text and stored in the database.
Especially, the selection of photovoltaic equipment directly affects the properties and parameters of equipment. And, the related parameters are as follows:

(1) Shape parameter $\alpha$

(2) Shape parameter $\beta$

(3) Single square array area $A$

(4) Energy conversion efficiency $\eta$

(5) Maximum solar irradiation $r_{\max }$

(6) PV capacity $S$

There are engineering restrictions on the location and capacity determination of PV equipment in actual scenarios. Hence, the location and capacity determination in photovoltaic system depends on manual operation in this software module. And, the built-in module can assess the operation status of distribution network, and its visual interface is shown in Figure 9. 


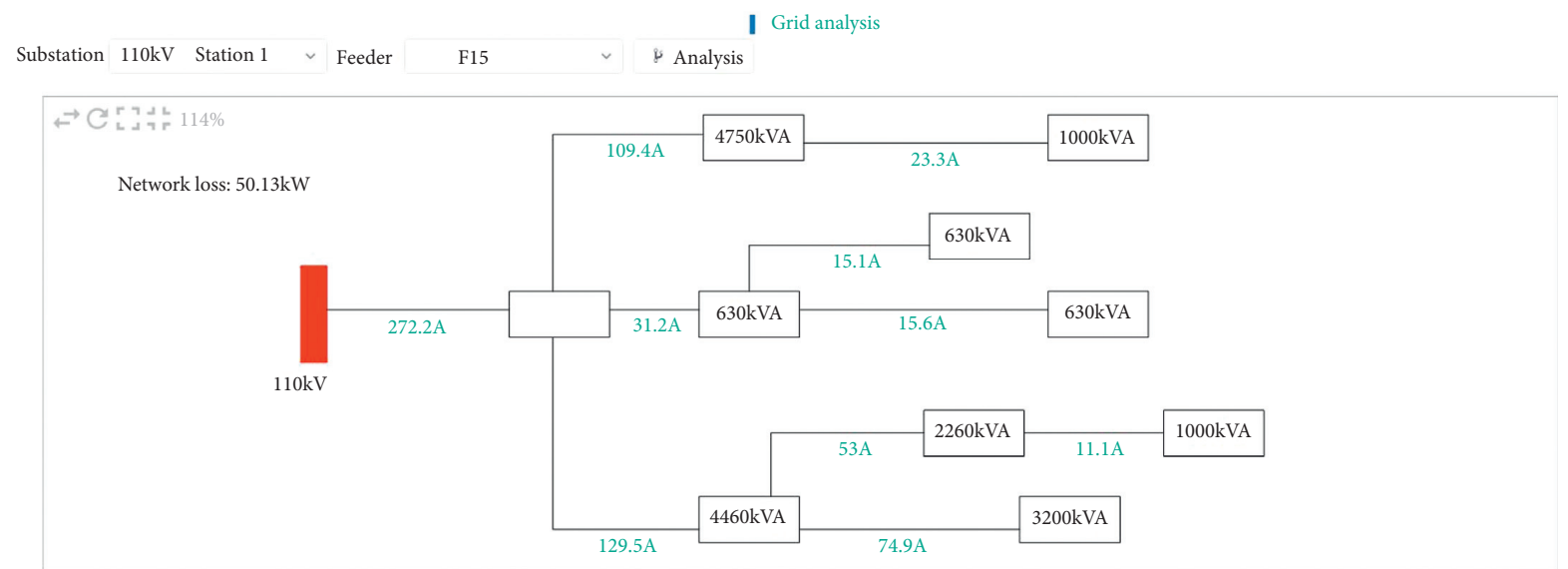

FIgURE 8: The display interface of calculated feeders.



Figure 9: The display interface of renewable energy connected planning.

\section{Conclusion}

This paper proposes the standardized information model and software of coordinated planning and energy conservation for distribution network, and the main contributions are as follows:

(1) The comprehensive index system of energy conservation and environmental protection for distribution network is presented, which provides a powerful tool to implement the evaluation and planning of the power system.

(2) The CIM file library of typical equipment in distribution network is established. This library is helpful for the intelligent planning of distribution network.

(3) The energy conservation and environmental protection software module is designed based on the CIM file which can be regarded as a general design scheme. 
(4) The designed indexes feature library can realize the improvement of software performance and background data capacity.

(5) The constructed power flow calculation module, carbon flow calculation module, and renewable energy connected planning module serve as the foundation for visual planning of distribution network.

Our next work will be promoted from the following two aspects:

(1) The functional modules of the software platform will continue to be expanded.

(2) The digitization and automation capabilities of the software will be enhanced, and a variety of machine learning core algorithms should be added.

\section{Data Availability}

The research data used to support the findings of this study are included within the article.

\section{Conflicts of Interest}

The authors declare that they have no conflicts of interest.

\section{Authors' Contributions}

T. W. conceptualized the study, developed to the methodology of the study, and wrote the original draft. H. C., C. G., and Z. L. carried out formal analysis, visualized the study, and obtained resources. T. Y. and R. C. reviewed and edited the article.

\section{Acknowledgments}

The authors gratefully acknowledge the support of the Science and Technology Project of China Southern Power Grid Corporation (GDKJXM20173256).

\section{References}

[1] J. A. Turner, "A realizable renewable energy future," Science, vol. 285, no. 5428, pp. 687-689, 1999.

[2] H. Lund, "Renewable energy strategies for sustainable development," Energy, vol. 32, no. 6, pp. 912-919, 2007.

[3] S. Kazemlou and S. Mehraeen, "Novel decentralized control of power systems with penetration of renewable energy sources in small-scale power systems," IEEE Transactions on Energy Conversion, vol. 29, no. 4, pp. 851-861, 2014.

[4] J. T. Boardman and C. C. Meckiff, "A branch and bound formulation to an electricity distribution planning problem," IEEE Transactions on Power Apparatus \& Systems, vol. 104, no. 8, pp. 2112-2118, 2007.

[5] S. K. Goswami, "Distribution system planning using branch exchange technique," IEEE Transactions on Power Systems, vol. 12, no. 2, pp. 718-723, 1997.

[6] N. Ponnavaikko, K. S. P. Rao, and S. S. Venkata, "Distribution system planning through a quadratic mixed integer programming approach," IEEE Transactions on Power Delivery, vol. 2, no. 4, pp. 1157-1163, 1987.
[7] I. J. Ramfrez-Rosado and J. A. Dommguez-Navarro, "New multiobjective tabu search algorithm for fuzzy optimal planning of power distribution systems," IEEE Transactions on Power Systems, vol. 21, no. 1, pp. 224-233, 2006.

[8] M. Shahbaz, C. Raghutla, K. R. Chittedi, Z. L. Jiao, and X. V. Vo, "The effect of renewable energy consumption on economic growth: evidence from the renewable energy country attractive index," Energy, vol. 207, Article ID 118162, 2020.

[9] P. S. N. Rao and R. Deekshit, "Energy loss estimation in distribution feeders," IEEE Transactions on Power Delivery, vol. 21, no. 3, pp. 1092-1100, 2006.

[10] V. Miranda, J. V. Ranito, and L. M. Proenca, "Genetic algorithms in optimal multistage distribution network planning," IEEE Transactions on Power Systems, vol. 9, no. 4, pp. 1927-1933, 1994.

[11] V. F. Martins and C. L. T. Borges, "Active distribution network integrated planning incorporating distributed generation and load response uncertainties," IEEE Transactions on Power Systems, vol. 26, no. 4, pp. 2164-2172, 2011.

[12] A. Soroudi and M. Ehsan, "A distribution network expansion planning model considering distributed generation options and techo-economical issues," Energy, vol. 35, no. 8, pp. 3364-3374, 2010.

[13] E. Miguez, J. Cidras, E. Diaz-Dorado, and J. L. Garcia-Dornelas, "An improved branch exchange algorithm for large scale distribution network planning," IEEE Power Engineering Review, vol. 22, no. 9, p. 58, 2002.

[14] I. J. Ramirez-Rosado and J. A. Dominguez-Navarro, "Possibilistic model based on fuzzy sets for the multiobjective optimal planning of electric power distribution networks," IEEE Transactions on Power Systems, vol. 19, no. 4, pp. 1801-1810, 2004.

[15] A. Soroudi, M. Ehsan, and H. Zareipour, "A practical ecoenvironmental distribution network planning model including fuel cells and non-renewable distributed energy resources," Renewable Energy, vol. 36, no. 1, pp. 179-188, 2011.

[16] M. Sedghi, A. Ahmadian, and M. Aliakbar-Golkar, "Assessment of optimization algorithms capability in distribution network planning: review, comparison and modification techniques," Renewable and Sustainable Energy Reviews, vol. 66, pp. 415-434, 2016.

[17] S. Essallah, A. Bouallegue, and A. Khedher, "Optimal sizing and placement of DG units in radial distribution system," International Journal of Renewable Energy Research (IJRER), vol. 8, no. 1, pp. 166-177, 2018.

[18] N. Acharya, P. Mahat, and N. Mithulananthan, "An analytical approach for dg allocation in primary distribution network," International Journal of Electrical Power \& Energy Systems, vol. 28, no. 10, pp. 669-678, 2006.

[19] M. F. Alhajri, M. R. Alrashidi, and M. E. El-Hawary, "Improved sequential quadratic programming approach for optimal distribution generation deployments via stability and sensitivity analyses," Electric Power Components and Systems, vol. 38, no. 14, pp. 1595-1614, 2010.

[20] Y. M. Atwa, E. F. El-Saadany, M. M. A. Salama, and R. Seethapathy, "Optimal renewable resources mix for distribution system energy loss minimization," IEEE Transactions on Power Systems, vol. 25, no. 1, pp. 360-370, 2010.

[21] K. M. S. Alzaidi, O. Bayat, and O. N. Uçan, "Multiple DGs for reducing total power losses in radial distribution systems using hybrid WOA-SSA algorithm," International Journal of Photoenergy, vol. 2019, Article ID 2426538, 20 pages, 2019. 
[22] M. M. Aman, G. B. Jasmon, A. H. A. Bakar, and H. Mokhlis, "A new approach for optimum simultaneous multi-DG distributed generation Units placement and sizing based on maximization of system loadability using HPSO (hybrid particle swarm optimization) algorithm," Energy, vol. 66, pp. 202-215, 2014. 